\title{
Gut memories do not fade: epigenetic regulation of lasting gut homing receptor expression in $\mathrm{CD} 4^{+}$ memory T cells
}

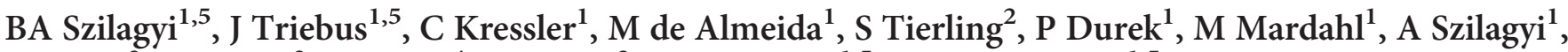 \\ S Floess $^{3}, \mathrm{~J} \mathrm{Huehn}^{3}$, U Syrbe ${ }^{4}, \mathrm{~J} \mathrm{Walter}^{2}$, JK Polansky ${ }^{1,5}$ and A Hamann ${ }^{1,5}$
}

The concept of a "topographical memory" in lymphocytes implies a stable expression of homing receptors mediating trafficking of lymphocytes back to the tissue of initial activation. However, a significant plasticity of the gut-homing receptor $\boldsymbol{\alpha}_{4} \boldsymbol{\beta}_{7}$ was found in CD8 ${ }^{+}$T cells, questioning the concept. We now demonstrate that $\alpha_{4} \boldsymbol{\beta}_{7}$ expression in murine $\mathrm{CD}^{+}{ }^{+}$memory Tcells is, in contrast, imprinted and remains stable in the absence of the inducing factor retinoic acid (RA) or other stimuli from mucosal environments. Repetitive rounds of RA treatment enhanced the stability of de novo induced $\alpha_{4} \boldsymbol{\beta}_{7}$. A novel enhancer element in the murine Itga4 locus was identified that showed, correlating to stability, selective DNA demethylation in mucosa-seeking memory cells and methylation-dependent transcriptional activity in a reporter gene assay. This implies that epigenetic mechanisms contribute to the stabilization of $\alpha_{4} \beta_{7}$ expression.

Analogous DNA methylation patterns could be observed in the human ITGA4 locus, suggesting that its epigenetic regulation is conserved between mice and men. These data prove that mucosa-specific homing mediated by $\alpha_{4} \beta_{7}$ is imprinted in $\mathrm{CD}^{+}$memory T cells, reinstating the validity of the concept of "topographical memory" for mucosal tissues, and imply a critical role of epigenetic mechanisms.

\section{INTRODUCTION}

Long-term immunity relies on memory cells providing protection against recurring infections. The shaping of functional features of memory cells during primary reactions includes the imprinting of migration properties that secure their optimal targeting to potentially affected compartments. This topographical memory, described as organ-specific homing more than 50 years ago, ${ }^{1}$ was a well-accepted paradigm that appeared to be supported by a number of studies on gutand skin-specific homing of $\mathrm{T}$ memory cells $\left(\mathrm{T}_{\mathrm{mem}}\right)$ generated in site-specific immune responses. ${ }^{2-4}$

Homing of $\mathrm{T}$ cells into distinct tissues depends on the expression of adhesion molecules and chemokine receptors. Naive $\mathrm{CD}^{+} \mathrm{T}$ cells $\left(\mathrm{T}_{\mathrm{N}}\right)$ uniformly recirculate through secondary lymphoid organs via L-selectin and CCR7, a behavior preserved by early stages of $\mathrm{T}_{\mathrm{mem}}$. However, upon further differentiation, $\mathrm{T}$ cells home preferentially into peripheral tissues such as the skin and gut or into inflamed sites. Eventually, part of the cells will become tissue-resident cells that stop circulating. ${ }^{5,6}$ In this study, we investigated the stability and molecular regulation of integrin $\alpha_{4} \beta_{7}$-dependent mucosa-specific homing of $\mathrm{CD} 44^{+} \mathrm{T}_{\text {mem }}$ from lymphoid tissues that largely belong to the recirculating pool of CD4 ${ }^{+} \mathrm{T}_{\text {mem }}$.

$\mathrm{T}$ cells homing to skin express $\mathrm{E}$ - and $\mathrm{P}$-selectin ligands and the chemokine receptor CCR4 and/or CCR8. By contrast, guthoming $\mathrm{T}_{\text {mem }}$ selectively express the integrin $\alpha_{4} \beta_{7}$ and partially express the chemokine receptor CCR9, enabling their entry into the intestine and associated lymphoid tissues by interacting with the mucosal addressin cell adhesion molecule-1 (MAdCAM-1) and the chemokine CCL25, respectively. ${ }^{7-9}$ Expression of these receptors is de novo induced or upregulated upon antigeninduced activation within mesenteric lymph nodes (mLNs) or

${ }^{1}$ Experimental Rheumatology, Charité Universitätsmedizin Berlin, and Deutsches Rheuma-Forschungszentrum Berlin, Berlin, Germany. ${ }^{2}$ Saarland University, FR8.3 Genetics/Epigenetics, Saarbrücken, Germany. ${ }^{3}$ Experimental Immunology, Helmholtz Centre for Infection Research, Braunschweig, Germany and ${ }^{4}$ Charité Universitätsmedizin Berlin, Medizinische Klinik für Gastroenterologie, Infektiologie und Rheumatologie, Berlin, Germany. Correspondence: A Hamann (hamann@drfz.de)

${ }^{5}$ These authors contributed equally to this work. 
Peyer's patches. ${ }^{10}$ The vitamin A metabolite retinoic acid (RA), provided by $\mathrm{CD}_{103}{ }^{+}$dendritic cells (DCs) and/or stromal cells in mLNs, ${ }^{11,12}$ has been identified as a crucial factor together with T-cell activation for induction of $\alpha_{4} \beta_{7}$ and CCR9. ${ }^{13}$

Notably, the assumption of the homing paradigm that $\mathrm{T}_{\text {mem }}$ cells acquire a stable homing phenotype by imprinted expression of a given set of adhesion receptors in $\mathrm{CD} 4{ }^{+} \mathrm{T}_{\text {mem }}$ only has been proven experimentally for selectin ligands so far. ${ }^{14,15}$ In fact, recent studies in $\mathrm{CD} 8{ }^{+} \mathrm{T}$ cells have rather demonstrated that the mucosal homing receptor $\alpha_{4} \beta_{7}$ is only transiently expressed on $\mathrm{CD}^{+} \mathrm{T}$ cells and that $\alpha_{4} \beta_{7}^{+}$gut-homing CD8 ${ }^{+} \mathrm{T}$ cells might convert into a skin-homing phenotype. ${ }^{16-18}$ This implied plasticity of migratory phenotypes and the possibility that certain homing phenotypes require continuous stimulation by environmental signals to be maintained.

In the first part of this study, we therefore investigated whether $\mathrm{CD}^{+} \mathrm{T}_{\text {mem }}$ retain expression of the gut-homing receptor $\alpha_{4} \beta_{7}$ in vivo or upon restimulation in vitro, or whether continuous instruction by tissue-localized factors is required for the maintenance of gut-homing properties. Indeed, ex vivo isolated $\alpha_{4} \beta_{7}^{+} \mathrm{CD}^{+}{ }^{+} \mathrm{T}_{\text {mem }}$ maintained their initial $\alpha_{4} \beta_{7}$ expression level independent of the presence of RA or other environmental factors encountered during recirculation through gut or gut-associated lymphoid tissues (GALTs). To acquire a stable phenotype, repeated stimulation of $\mathrm{T}_{\mathrm{N}}$ cells in the presence of RA was required, suggesting a stepwise acquisition of an imprinted state.

In a second part, we analyzed the molecular basis for the imprinted phenotype. The regulation of $\alpha_{4}$-integrins is not well understood, despite significant medical relevance of $\alpha_{4}$-integrins as a target for antibody therapies in chronic inflammatory bowel disease and multiple sclerosis.
Here we focused on the role of epigenetic mechanisms, as a growing list of evidence suggests that DNA methylation or histone modifications might be the key for a stably imprinted expression pattern in polarized T-helper (Th) subsets, stable lineages such as regulatory $\mathrm{T}$ cells, expression of signature cytokines, or master transcription factors. ${ }^{19-22}$ Albeit it appears suggestive, homing receptors have hardly been analyzed in this respect so far.

While some histone modifications appear to be solely associated with current transcriptional activity, notably DNA methylation and other repressive mechanisms are key candidates for the regulation of a long-term, heritable phenotype. ${ }^{23}$ We therefore analyzed the DNA methylation patterns of the Itga4 locus-coding for the integrin $\alpha_{4}$ chain-in murine and human T cell subsets. Indeed, differential DNA methylation was observed in distinct regulatory regions and appears to control the stability of Itga4 expression.

\section{RESULTS \\ Stable expression of $\alpha_{4} \beta_{7}$ on murine CD4 ${ }^{+}$memory T cells in vivo}

First, the stability of $\alpha_{4} \beta_{7}$ expression on murine CD4 ${ }^{+} \mathrm{T}_{\text {mem }}$ was analyzed in vivo. For this, we labeled ex vivo isolated, highly pure $\alpha_{4} \beta_{7}^{+}$and $\alpha_{4} \beta_{7}^{-} \mathrm{CD}_{45 \mathrm{RB}}{ }^{\text {low }} \mathrm{CD} 4{ }^{+} \mathrm{T}_{\text {mem }}$ subsets (Supplementary Figure 1A online) with CFSE, transferred them into recipient mice and reanalyzed $\alpha_{4} \beta_{7}$ expression on transferred cells 15 days (Figure 1a and b) or 6 weeks later (Figure 1c). The majority of $\alpha_{4} \beta_{7}^{+} \mathrm{CD} 4^{+} \mathrm{T}_{\text {mem }}$ maintained high $\alpha_{4} \beta_{7}$ expression for at least 6 weeks, whereas transferred $\alpha_{4} \beta_{7}^{-} \mathrm{CD}^{+} \mathrm{T}_{\text {mem }}$ remained negative for $\alpha_{4} \beta_{7}$. These data show that the expression of $\alpha_{4} \beta_{7}$ in $\mathrm{CD}^{+}{ }^{+} \mathrm{T}_{\text {mem }}$ is stable in vivo. Interestingly, some $\alpha_{4} \beta_{7}^{+} \mathrm{CD} 4^{+} \mathrm{T}_{\text {mem }}$ were also recovered
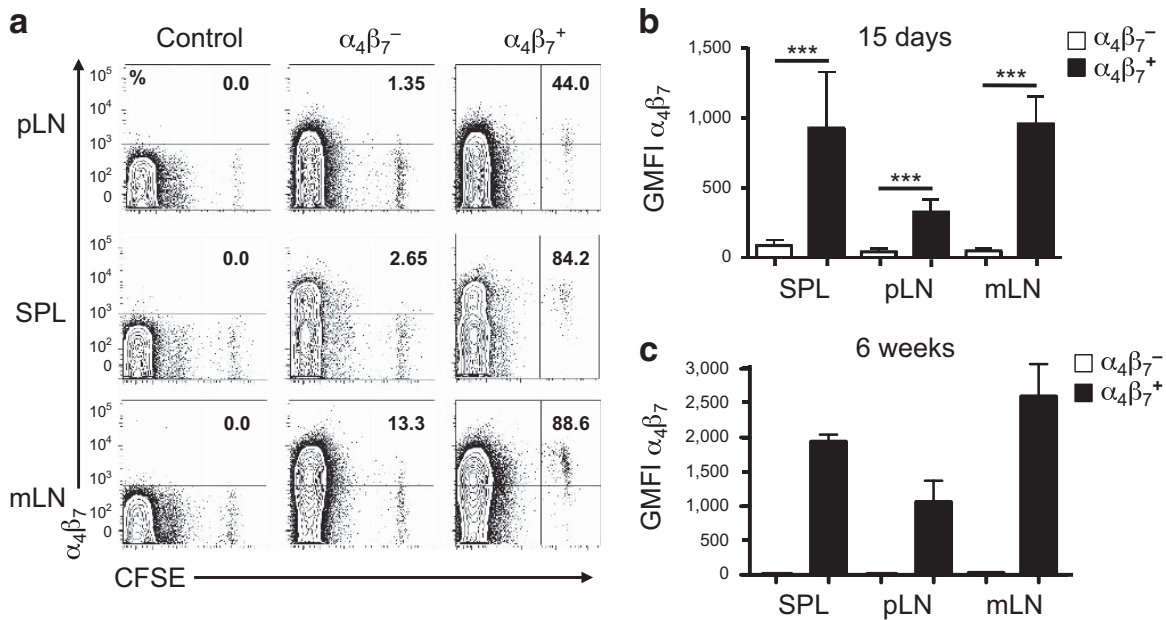

Figure 1 Stable expression of integrin $\alpha_{4} \beta_{7}$ on ex vivo isolated CD4 ${ }^{+} \mathrm{T}_{\mathrm{mem}}$. (a and $\left.\mathbf{b}\right) \alpha_{4} \beta_{7}$ Expression on $\mathrm{T}_{\text {mem }} 15$ days after adoptive transfer. Ex vivo

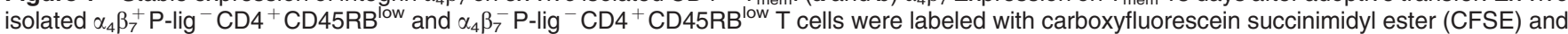
transferred into recipient mice. Fifteen days after transfer, cells from peripheral lymph node ( $\mathrm{pLN})$, mesenteric lymph node $(\mathrm{mLN})$, and spleen $(\mathrm{SPL})$ were reanalyzed for $\alpha_{4} \beta_{7}$ expression. Representative FACS (fluorescence-activated cell sorter) plots from three independent experiments are shown in (a). Control: staining control FMO- $\alpha_{4} \beta_{7}$ (fluorescence minus one). Numbers indicate frequencies of $\alpha_{4} \beta_{7}^{+}$cells in transferred CFSE ${ }^{+}$cells. Accumulated values from three independent experiments $\left(\alpha_{4} \beta_{7}^{-}, n=6 ; \alpha_{4} \beta_{7}^{+}, n=9\right)$ are shown in (b) as mean $\pm \mathrm{s}$.d. of pooled geometric mean fluorescence intensity (GMFI) of CFSE + cells. (c) $\alpha_{4} \beta_{7}$ Expression 6 weeks after transfer. Mean \pm s.d. of pooled GMFI data from three or four mice in three experiments. Student's $t$-test with ${ }^{* *} P<0.001$. 
from the subcutaneous peripheral lymph nodes (pLNs), albeit with reduced levels of retained $\alpha_{4} \beta_{7}$ compared with the spleen or mLN. This might be due to the heterogeneity of the transferred $\mathrm{CD}_{45} \mathrm{RB}^{\text {low }} \mathrm{CD}^{+}$population, which contains, besides $\alpha_{4} \beta_{7}^{+}$effector/memory cells, central memory T cells (Supplementary Figure 1A and B), which coexpress other homing receptors such as L-selectin (CD62L). L-selectin controls pLN immigration and is likely to cause enrichment of the $\mathrm{CD} 62 \mathrm{~L}^{+}$fraction at this site.

\section{Stable expression of $\alpha_{4} \beta_{7}$ on murine $\mathrm{CD}^{+}{ }^{+} \mathrm{T}_{\text {mem }}$ depends neither on stabilizing factors within the GALT nor on the presence of RA}

The observed in vivo stability could be mediated either by a cellintrinsic imprinting of $\alpha_{4} \beta_{7}$ expression or by continual encounter with environmental signals required for its maintenance. As $\alpha_{4} \beta_{7}$ is induced by the vitamin A metabolite RA, ${ }^{13}$ we asked whether the maintained expression of $\alpha_{4} \beta_{7}$ in vivo depends on the presence of RA.

To investigate this question, we generated vitamin A-deficient mice by pre- and postnatal feeding of a vitamin A-deficient diet for at least 14 weeks and used them as recipients for adoptive transfer of $\alpha_{4} \beta_{7}^{+}$and $\alpha_{4} \beta_{7}^{-} \mathrm{CD} 4{ }^{+} \mathrm{T}_{\text {mem }}$. As shown in Figure 2a, the expression of $\alpha_{4} \beta_{7}$ on transferred $\mathrm{CD} 4^{+} \mathrm{T}_{\text {mem }}$ was not affected by vitamin A deficiency. By contrast, endogenous $T$ cells displayed low levels of $\alpha_{4} \beta_{7}$ under these conditions (Figure 2a), and naive OVA-specific $\mathrm{CD} 4{ }^{+} \mathrm{T}$ cells transferred into vitamin A-deficient mice failed to upregulate $\alpha_{4} \beta_{7}$ and CCR9 upon oral application of OVA protein and cholera toxin (Figure 2b). This proved the effective removal of RA from the system. The data indicate that while RA is critical for the de novo induction of $\alpha_{4} \beta_{7}$, it is not required for the maintenance of $\alpha_{4} \beta_{7}$ on $\mathrm{CD} 4^{+} \mathrm{T}_{\text {mem. }}$.

$\mathrm{T}_{\text {mem }}$ residing in secondary lymphoid tissues are known to recirculate to some extent between blood, lymph, and tissues. ${ }^{24,25}$ We therefore asked whether local factors in the gut or GALT were required for the stability of $\alpha_{4} \beta_{7}$ expression in $\mathrm{CD} 44^{+} \mathrm{T}_{\text {mem }}$. To prevent access of CD4 ${ }^{+} \mathrm{T}_{\text {mem }}$ to mucosal sites, we blocked the adhesion molecules MAdCAM-1 and vascular cell adhesion molecule-1 (VCAM-1) involved in the entry of lymphocytes into this compartment by injection of antiMAdCAM-1 and anti-VCAM-1 antibodies. This treatment reduced the entry of $\mathrm{CD} 4{ }^{+} \mathrm{T}_{\text {mem }}$ into both gut and GALT by 85-95\% (Supplementary Figure 2). To examine whether the maintenance of $\alpha_{4} \beta_{7}$ expression depends on gut-derived instructive signals, we transferred $\alpha_{4} \beta_{7}^{+} \mathrm{CD} 4^{+} \mathrm{T}_{\text {mem }}$ into recipient mice together with injection of either anti-MAdCAM1 plus anti-VCAM-1 antibodies or a rat-immunoglobulin G (IgG) control antibody. Antibody treatment was repeated every 3 days until analysis on day 15, resulting in the exclusion of transferred $\mathrm{CD} 4{ }^{+} \mathrm{T}_{\mathrm{mem}}$ from the gut and GALT and their accumulation in the spleen (Figure $2 \mathrm{c}$ and Supplementary Figure 2). These conditions did not result in any reduction of $\alpha_{4} \beta_{7}$ expression on transferred $\alpha_{4} \beta_{7}^{+} \mathrm{CD}^{+}{ }^{+} \mathrm{T}_{\text {mem }}$ (Figure 2c), suggesting that the maintenance of $\alpha_{4} \beta_{7}$ expression, in contrast to its induction on $\mathrm{T}_{\mathrm{N}}$ cells, is independent of signals provided within the gut and GALT, but relies on a cell-intrinsic mechanism.

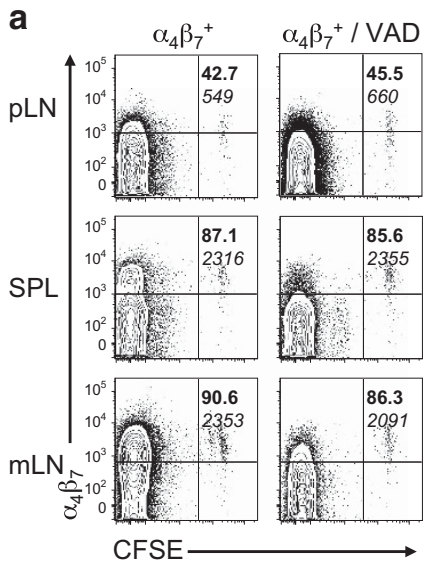

b

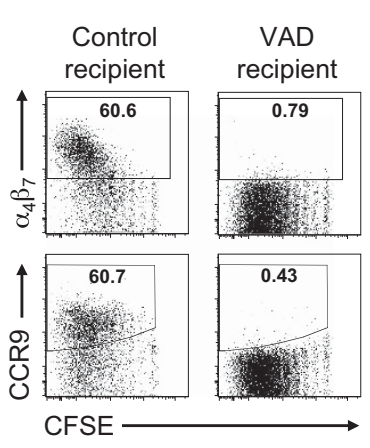

c

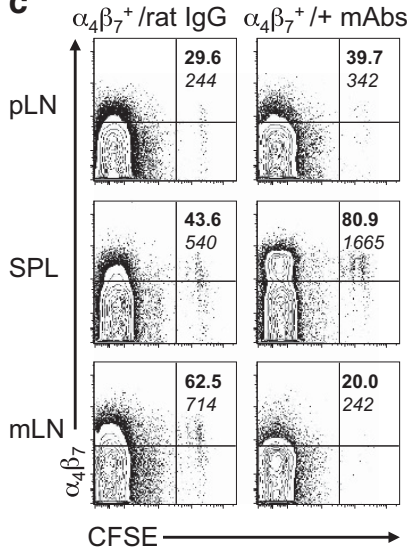

Figure 2 Stable expression of integrin $\alpha_{4} \beta_{7}$ on ex vivo isolated $T_{\text {mem }}$ after transfer into vitamin A-deficient mice or exclusion from

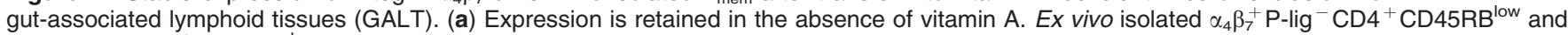
$\alpha_{4} \beta_{7}^{-}$P-lig ${ }^{-}$CD4 ${ }^{+}$CD45RB ${ }^{\text {low }}$ T cells were labeled with carboxyfluorescein succinimidyl ester (CFSE) and transferred into control or vitamin A-depleted (VAD) mice. After 15 days, transferred cells were reanalyzed for $\alpha_{4} \beta_{7}$ expression. At 15 days after transfer, cells from peripheral lymph node (pLN), mesenteric lymph node (mLN) and spleen (SPL) were isolated and reanalyzed for $\alpha_{4} \beta_{7}$ expression. Representative FACS (fluorescence-activated cell sorter) plots from three independent experiments with eight mice; the frequency of $\alpha_{4} \beta_{7}^{+}$cells (bold) and geometric mean fluorescence index (GMFI) (italic) among transferred cells is given. (b) Lack of $\alpha_{4} \beta_{7}$ and CCR9 upregulation verifies depletion of vitamin A. CFSE-labeled Ova-specific $\mathrm{CD}^{+}{ }^{\mathrm{CD}} 62 \mathrm{~L}^{\text {high }} \mathrm{T}$ cells from DO11.10 mice were injected into control or VAD mice. At $24 \mathrm{~h}$ after transfer, mice were immunized with Ova protein and cholera toxin by oral gavage. On day 4 after immunization, analysis of $\alpha_{4} \beta_{7}$ expression on OVA-specific (KJ71-16 ${ }^{+}$) cells was performed by flow cytometry. Plots are gated on transferred $\mathrm{KJ}^{+}$cells. (c) Expression of $\alpha_{4} \beta_{7}$ is retained upon exclusion from GALT. Ex vivo FACS-sorted $\alpha_{4} \beta_{7}^{+}$P-lig ${ }^{-}$CD4 $^{+}{ }^{+}$CD45RB $^{\text {low }}$ and $\alpha_{4} \beta_{7}^{-}$P-lig ${ }^{-}$CD4 ${ }^{+}$CD45RB $^{\text {low }}$ T cells were labeled with CFSE and transferred into recipient mice. To exclude $\alpha_{4} \beta_{7}^{+} \mathrm{T}_{\text {mem }}$ from GALT recipient mice received anti-MAdCAM-1 (Meca367; $500 \mu \mathrm{g}$ per mouse) and anti-VCAM-1 Abs (6C7.1; 200 $\mu \mathrm{g}$ per mouse) or, as control, rat IgG intravenously at the day of cell transfer and then every 3 days until the day of analysis. Representative FACS plot from three independent experiments with four mice; the frequency of $\alpha_{4} \beta_{7}^{+}$cells and GMFI among transfered CFSE ${ }^{+}$cells is given. 
$\alpha_{4} \beta_{7}$, but not CCR9, displays stability on murine $T_{\text {mem }}$ during in vitro culture

We tested ex vivo sorted $\alpha_{4} \beta_{7}^{+} \mathrm{CD} 4^{+} \mathrm{T}_{\text {mem }}$ for their phenotypic stability in in vitro cultures and observed that they largely retained $\alpha_{4} \beta_{7}$ expression upon restimulation (Figure 3a), confirming the imprinted state of $\alpha_{4} \beta_{7}$ in memory cells. Notably, expression was retained not only in the absence of RA but also in the presence of interleukin-12 (IL-12), which is known to upregulate the competing homing receptors P- and E-selectin ligands ("skin-homing phenotype"). ${ }^{26,27}$ Selectin ligands are expressed in $\mathrm{T}_{\mathrm{mem}}$, but, for ex vivo isolated cells, in a largely mutually exclusive way to $\alpha_{4} \beta_{7}$ (see Figure 6 and Supplementary Figure 1).

Besides $\alpha_{4} \beta_{7}$, the chemokine receptor CCR9 is also induced by RA. CCR9 is thought to have a role in the immigration of cells to the small intestine; however, in accordance with previous reports, ${ }^{16}$ only a small fraction of-mostly $\alpha_{4} \beta_{7}^{+}-$ $\mathrm{CD} 4^{+} \mathrm{T}_{\mathrm{mem}}$ from mLNs and spleen express this receptor. When ex vivo-sorted CCR9 ${ }^{+} \mathrm{T}_{\text {mem }}$ were stimulated in vitro, CCR9 was almost completely lost in the absence but retained in the presence of RA (Figure 3b), suggesting that CCR9 is not imprinted in $\mathrm{CD}^{+}{ }^{+} \mathrm{T}_{\text {mem }}$ but requires continual RA signals from the environment to remain expressed. These data add further evidence to previous findings, suggesting that the regulation of the gut-homing receptors $\alpha_{4} \beta_{7}$ and CCR9 differs. ${ }^{28,29}$
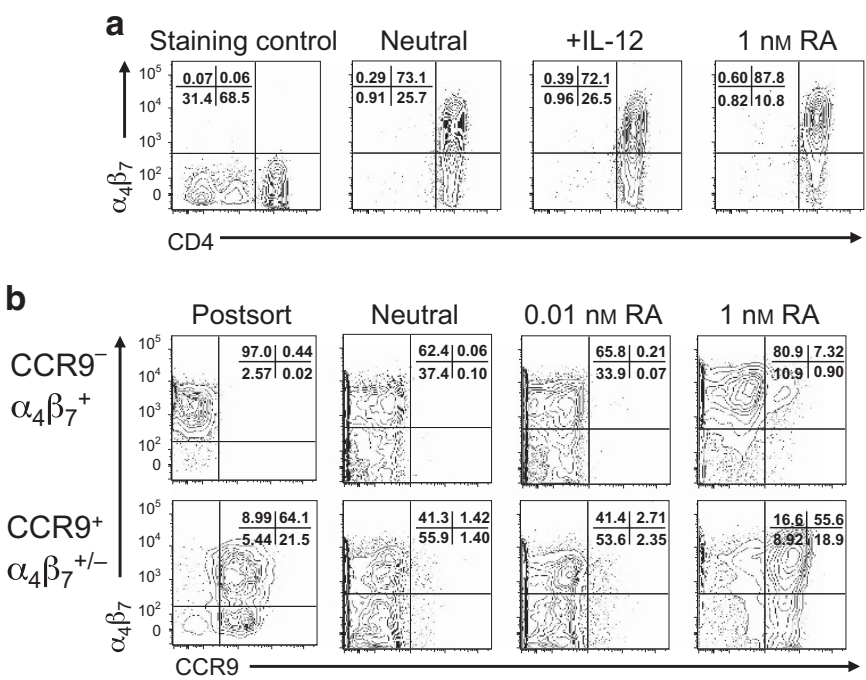

Figure 3 Integrin $\alpha_{4} \beta_{7}$, but not CCR9, expression is stably imprinted within ex vivo isolated $T_{\text {mem. }}$. (a) Ex vivo isolated $\alpha_{4} \beta_{7}^{+} \mathrm{P}$ -

$\mathrm{lig}^{-} \mathrm{CD} 4{ }^{+} \mathrm{CD} 45 \mathrm{RB}^{\mathrm{low}} \mathrm{T}$ cells were stimulated with plate-bound anti-CD3/ 28 antibodies and interleukin-2 (IL-2) in the presence or absence of retinoic acid (RA) (1 nm) and IL-12 $\left(5 \mathrm{ng} \mathrm{ml}^{-1}\right)$. On day 5, cells were harvested and analyzed for homing receptor expression by flow cytometry. Some unstained cells (lower left quadrant) were added in the staining control to facilitate compensation. (b) Ex vivo isolated CCR9 ${ }^{-}$

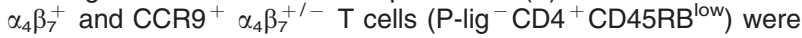
stimulated with plate-bound anti-CD3/28 antibodies and IL-2 in the presence or absence of RA ( 0.1 and $1 \mathrm{~nm})$. On day 5 , cells were analyzed for $\alpha_{4} \beta_{7}$ and CCR9 expression. FACS (fluorescence-activated cell sorter) plots are representative of three independent experiments each performed in (a) triplicates or (b) duplicates.
Repetitive, but not single, stimulation in the presence of RA stabilizes $\alpha_{4} \beta_{7}$ expression

$\alpha_{4} \beta_{7}$ Expression can be induced in CD4 ${ }^{+}$T cells by RA, but it is unclear whether this is sufficient to achieve stable $\alpha_{4} \beta_{7}$ expression as found in $\mathrm{CD}^{+} \mathrm{T}_{\text {mem }}$. Therefore, we induced $\alpha_{4} \beta_{7}$ expression on murine $\mathrm{CD}^{-} 5^{-} \mathrm{CD} 4{ }^{+} \mathrm{CD} 2 \mathrm{~L}^{+} \mathrm{T}_{\mathrm{N}}$ cells during in vitro activation in the presence of RA and anti-IL-4 antibody (IL- 4 has been reported to influence negatively $\alpha_{4} \beta_{7}$ induction in vitro). ${ }^{16}$ On days 5 and 11 of culture, the cells were restimulated in the absence or presence of RA. $\alpha_{4} \beta_{7}$ Expression was analyzed at days 5,11 , and 17 . As expected, $\mathrm{T}$-cell activation in the presence of RA resulted in the efficient upregulation of $\alpha_{4} \beta_{7}$ (Figure 4a and $\mathbf{b}$ ). However, in vitro-generated $\alpha_{4} \beta_{7}^{+} \mathrm{T}$ cells rapidly lost $\alpha_{4} \beta_{7}$ expression when restimulated for 5 days in the absence of RA. Only $\alpha_{4} \beta_{7}^{+}$T cells that had been stimulated two times in the presence of RA maintained $\alpha_{4} \beta_{7}$ expression upon restimulation in the absence of RA (Figure $4 \mathbf{a}$ and $\mathbf{b}$ ). Thus, repetitive stimulation with RA, in contrast to single treatment, was sufficient to stabilize $\alpha_{4} \beta_{7}$ expression in vitro, suggesting that imprinting of $\alpha_{4} \beta_{7}$ expression in $\mathrm{T}$ cells requires a repeated or prolonged encounter with instructive signals.

Consistent with the in vitro stability, repeatedly RA-treated $\mathrm{T}$ cells retained a higher expression of $\alpha_{4} \beta_{7}$ compared with control cells on day 15 after transfer into recipient mice (Figure 4c), albeit the expression level was lower than at the time of transfer. This indicates that repetitive rounds of stimulation in the presence of RA resulted in at least a partial stabilization of $\alpha_{4} \beta_{7}$ expression in T cells.

Two regulatory elements in the murine Itga4 locus show epigenetic modifications correlating with the stability of $\alpha_{4} \beta_{7}$ expression

Cell-intrinsic imprinting of a given gene activity state often relies on mechanisms of epigenetic regulation such as DNA methylation of critical genomic elements. We therefore performed a pilot MeDIP-on-Chip experiment to search for potential differentially methylated regions in the Itga4 and Itgb7 loci in ex vivo $\alpha_{4} \beta_{7}^{+}$vs. $\alpha_{4} \beta_{7}^{-} \mathrm{CD} 4^{+} \mathrm{T}_{\text {mem }}$ subsets (data not shown). Differential methylation was apparent in two regions in the Itga4 locus: the Itga 4 promoter upstream of the transcription start site containing a CpG-island (CpG-I), and a region in the second intron, which we termed differentially methylated region 1 (dmr1), both containing several CpG motifs (Figure 5a). No dmr were observed in the Itgb7 locus. In line with previous reports, ${ }^{30}$ we found only Itga4, but not Itgb7, to be regulated by repetitive RA treatment (Supplementary Figure 3). For these reasons, we focused our efforts on clarifiying the mechanism for the stability of $\alpha_{4} \beta_{7}$ expression on the Itga4 locus.

We tested both regions in the Itga4 gene for their regulatory activity on transcription using a classic luciferase reporter assay in murine $\mathrm{CD} 4^{+} \mathrm{T}$ cells (Figure $\mathbf{5 b}$ and $\mathbf{c}$ ). As expected, the Itga4 promoter (but not dmr1; Figure 5b) was able to induce expression of the luciferase reporter, whereas the $\mathrm{dmr} 1$ element displayed an enhancer function when tested in conjunction with a promoter (Figure 5c). 
a

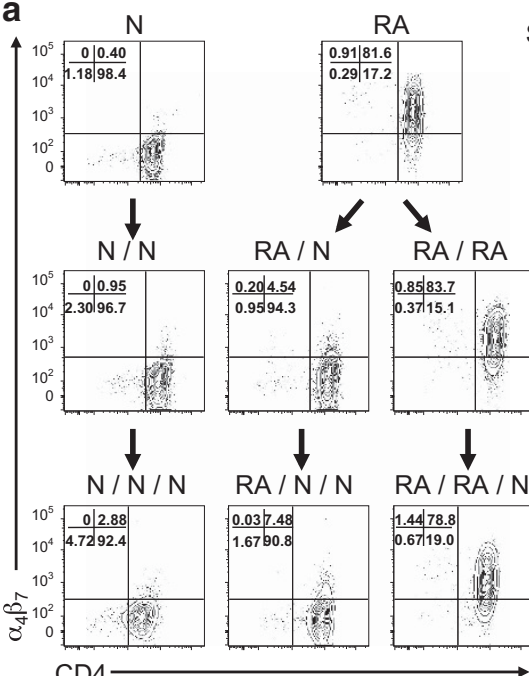

Stimulation round

/ day of analysis

1 st/day 5

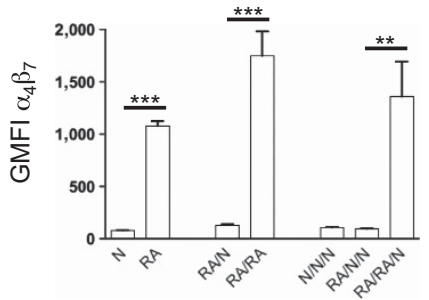

2nd/day 11

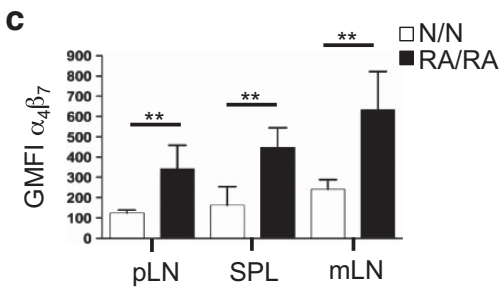

Figure 4 Repetitive, but not single, stimulation in the presence of retinoic acid (RA) stabilizes $\alpha_{4} \beta_{7}$ expression on CD4 ${ }^{+} \mathrm{T}_{\mathrm{N}}$ cells in vitro. (a and $\left.\mathbf{b}\right) \mathrm{CD} 4{ }^{+}$ $\mathrm{T}_{\mathrm{N}}$ cells were TCR stimulated (1st round) in vitro with plate-bound anti-CD3/CD28 antibodies under neutral ("N" = no further supplements) or polarizing conditions with RA ( $1 \mathrm{~nm}$ ) and anti-IL-4 antibody ("RA"). TCR stimulation with one of the two conditions was repeated on day 5 (2nd round) and on day 11 (3rd round). Cells were analyzed for $\alpha_{4} \beta_{7}$ expression before restimulation on day 5, 11, and 17. (a) Representative FACS (fluorescence-activated cell sorter) plots and (b) accumulated data from three replicates (mean \pm s.d. of geometric mean fluorescence index (GMFI)) of one representative out of three independent experiments are shown. (c) Stability of $\alpha_{4} \beta_{7}$ expression in vivo. CD4 ${ }^{+} \mathrm{T}_{\mathrm{N}}$ cells were stimulated two times with plate-bound anti-CD3/CD28 antibodies with or without RA and anti-IL-4 antibody as above. On day 11, cells were labeled with carboxyfluorescein succinimidyl ester (CFSE) and transferred into recipient mice. Isolation and analysis were carried out on day 15 after transfer. Mean $\pm \mathrm{s}$.d. of pooled GMFI data from two out of three independent experiments with $n=4$ or 5 mice in total. Student's $t$-test with ${ }^{\star \star} P<0.01$ and ${ }^{* \star \star} P<0.001$.

Next, we designed amplicons on both regions to analyze the methylation status in $\mathrm{CD} 4^{+} \mathrm{T}$ cells. As the promoter contained a large CpG-I, which was largely demethylated (data not shown), we concentrated our analysis on two CpG motifs in the CpG-I shore. Shores of CpG-I have been reported to contain most of the dynamic methylation-dependent regulatory capacity, whereas CpG-Is are usually uniformly demethylated in most promoters. ${ }^{31}$ Indeed, we found significant demethylation of the two CpG-I shore CpGs in $\alpha_{4} \beta_{7}^{+} \mathrm{CD} 4^{+} \mathrm{T}_{\text {mem }}$ as well as in T cells repeatedly stimulated in the presence of RA (Figure 5d). Their $\alpha_{4} \beta_{7}^{-}$counterparts $\left(\alpha_{4} \beta_{7}^{-} \mathrm{P}\right.$-lig ${ }^{+} \mathrm{T}_{\mathrm{mem}}$, expressing the inflammation/skin-related homing receptor $\mathrm{P}$-selectin ligand (P-lig), as well as T cells stimulated in the presence of the RA antagonist LE540), displayed high methylation levels. Interestingly, ex vivo-isolated $\mathrm{T}_{\mathrm{N}}$ cells, which have not yet undergone imprinting for a certain homing phenotype, showed an equally low degree of methylation, suggesting that these cells are permissive for the expression of $\alpha_{4} \beta_{7}$ in the presence of appropriate conditions, whereas stimulation in the absence of RA signaling or differentiation into skin-homing $\mathrm{T}_{\text {mem }}$ promotes acquisition of an inhibitory epigenetic mark at the promoter.

Analysis of seven CpGs in dmr1 showed a significant demethylation in $\alpha_{4} \beta_{7}^{+}$vs. $\alpha_{4} \beta_{7}^{-} \mathrm{CD} 4^{+} \mathrm{T}_{\text {mem }}$, whereas RAinduced $\alpha_{4} \beta_{7}^{+}$T cells displayed only small differences from their counterparts treated with the RA antagonist LE540 or uncommited $\mathrm{T}_{\mathrm{N}}$ cells (Figure 5e). These data indicate that the methylation level in dmr1 qualifies as a stabilizer for Itga4 expression in fully imprinted $\alpha_{4} \beta_{7}^{+} \mathrm{CD} 4^{+} \mathrm{T}_{\text {mem }}$, whereas repetitive stimulation in vitro in the presence of RA might not be sufficient to achieve full epigenetic fixation at this regulatory element. As further support for this conclusion, we found increased stability of $\alpha_{4} \beta_{7}$ expression in murine $T_{N}$, which were treated with the DNA-demethylating drug 5-azacytidine during the RA-mediated induction phase (Supplementary Figure 4).

To confirm the putative methylation-dependent enhancer/ stabilizer function of dmr1, we cloned the dmr1 into a CpG-free luciferase reporter ${ }^{32}$ - which allows selective in vitro methylation of inserted $\mathrm{CpG}$-containing sequences- and performed reporter gene assays in primary murine $\mathrm{T}$ cells. Indeed, the enhancer activity of dmrl was strongly compromised upon methylation (Figure 5c), supporting a functional link between DNA methylation and transcriptional activity.

\section{The human ITGA4 gene also shows epigenetic modification in $\alpha_{4} \beta_{7}^{+}$vs. $\alpha_{4} \beta_{7}^{-}$CD4 ${ }^{+}$T cells}

The murine Itga 4 and human ITGA4 loci show a high degree of structural similarity (Figure 6a) even if the sequence homology is variable. Therefore, similar regulatory mechanisms might apply. Using whole-genome bisulfite sequencing data of human $\mathrm{CD}^{+} \mathrm{T}$ cells generated in the context of the German Epigenome Programme "DEEP", 33 we analyzed the ITGA4 promoter and searched for regions that were differentially methylated between naive and memory cells and might correspond to the murine dmrl. Two DMR were identified for which amplicons for the detailed analysis of DNA methylation were designed (Figure 6a).

Similar to murine T cells, $\alpha_{4} \beta_{7}^{+} \mathrm{CD} 4^{+}$T cells are found in the memory T-cell fraction in human peripheral blood and $\alpha_{4} \beta_{7}$ 


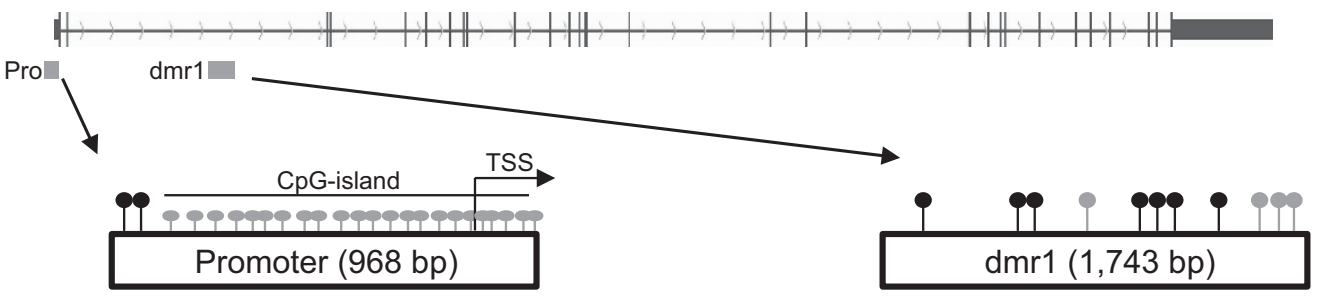

b

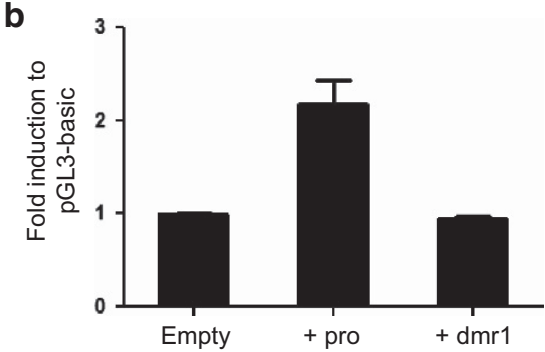

d

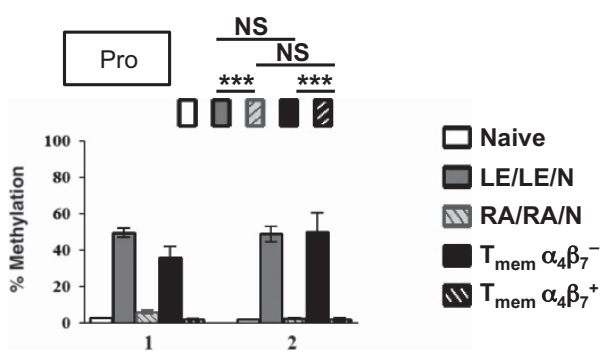

C

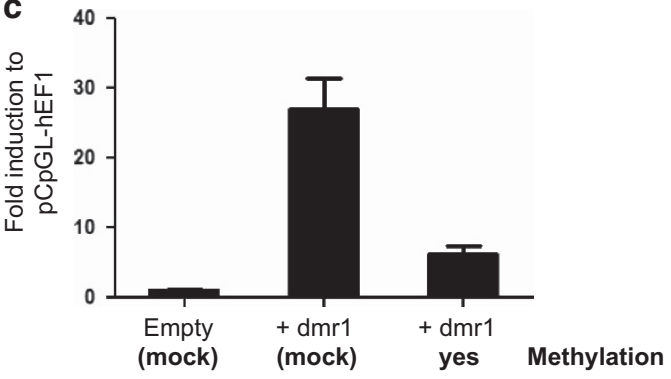

e

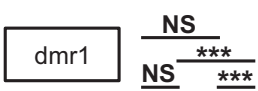

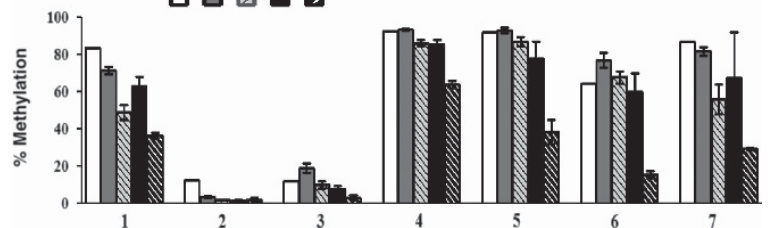

Figure 5 The promoter and an intronic enhancer in the murine Itga4 locus show transcriptional activity and differential DNA methylation patterns. (a) The genomic organization of the murine Itga4 locus is shown with the position of the analyzed promoter (pro) and enhancer (differentially methylated region 1 (dmr1)) region. The position of $\mathrm{CpG}$ motifs within the promoter and in the $\mathrm{dmr} 1$ region used in ( $\mathbf{b}$ and $\mathbf{c}$ ) are shown as needle heads. CpG motifs shown in black were analyzed for methylation in (d and $\mathbf{e})$. (b and $\mathbf{c}$ ) The Itga4 pro and the dmr1 enhancer show promoter or methylation-sensitive enhancer activity, respectively. (b) The Itga4 promoter and the dmr1 region were cloned into the promoter-free pGL3 luciferase reporter plasmids (pGL3basic) and tested for transcriptional promoter activity in murine CD4 ${ }^{+}$Th1 cells in a luciferase reporter assay. In addition, dmr1 was tested in a CpG-free luciferase reporter vector (pCpGL-hEF1) containing the hEF1 promoter. This vector allows application of in vitro methylation (and mock methylation as control), as this affects only the cloned insert. (c) With this approach, the methylation sensitivity of the enhancer function of dmr1 was assessed in primary murine CD4 ${ }^{+}$T cells. (d and $\mathbf{e}$ ) The degree of DNA methylation of selected CpG motifs (shown in a as black needle heads) in the (d) Itga4 promoter and (e) dmr1 was analyzed by bisulfite sequencing of $\mathrm{T}_{\mathrm{N}}(n=2)$ and ex vivo isolated $\alpha_{4} \beta_{7}^{+}$or $\alpha_{4} \beta_{7}^{-} \mathrm{P}$-lig ${ }^{+} \mathrm{T}_{\text {mem }}\left(n=3\right.$ each), as well as of cultured $\mathrm{T}_{\mathrm{N}}$ after two rounds of retinoic acid (RA) or LE540 treatment followed by a final round in the absence of both additives $(\mathrm{N})(n=3$ each). Mean ( \pm s.d., if $n>2)$ methylation values for each CpG motif are given. Statistical significance of differences between all analyzed CpG motifs of the respective cell types in a given region was tested as described in the Method section. Significant differences are indicated: ${ }^{\star \star \star} P<0.001$ and NS, not significant. TSS, transcription start site.

expression is mutually exclusive to expression of the skinhoming receptor and E-selectin ligand CLA (Figure $6 \mathbf{b}$ ). In the naive fraction of human CD4 ${ }^{+}$cells, both $\alpha_{4} \beta_{7}^{+}$and $\alpha_{4} \beta_{7}^{-}$cells can be detected using the very bright Act-1-PE antibody (Figure 6b), a finding of unknown biological significance that was not reported before and is not observed in murine cells. Compared with $\mathrm{T}_{\text {mem }}, \alpha_{4} \beta_{7}^{+} \mathrm{T}_{\mathrm{N}}$ cells express detectable, but intermediate, levels of $\alpha_{4} \beta_{7}$ (Figure 6b). We analyzed the degree of DNA methylation for six CpGs in the CpG-I shore of the promoter as well as for DMR1 and DMR2.

Methylation of the analyzed CpGs in the CpG-I shore of the promoter was generally at a low level, but lowest in the $\alpha_{4} \beta_{7^{-}}$ expressing populations of both $\mathrm{T}_{\mathrm{N}}$ and $\mathrm{T}_{\text {mem }}$ cells (Figure $6 \mathrm{c}$ and f). As observed in murine cells, the highest methylation was found in $\alpha_{4} \beta_{7}^{-}$(and CLA ${ }^{+}$) memory cells, suggesting an epigenetic silencing of ITGA4 during differentiation into skinhoming $\mathrm{T}_{\mathrm{mem}} . \alpha_{4} \beta_{7}^{-}$-naive $\mathrm{T}$ cells displayed an intermediate methylation state, suggesting that they are predisposed to ITGA4 expression upon appropriate signaling.

For DMR1, fully commited $\alpha_{4} \beta_{7}^{+}$CLA ${ }^{-} \mathrm{T}_{\text {mem }}$ were the only cell type displaying consistently low levels of methylation among the CpGs of this region, indicating that DMR1 might serve as a stabilizer element (Figure $\mathbf{6 d}$ and $\mathbf{f}$ ). The $\alpha_{4} \beta_{7}^{+}$ fraction of $\mathrm{T}_{\mathrm{N}}$ showed a tendency towards decreased methylation compared with the $\alpha_{4} \beta_{7}^{-}$cell types, which, however, lacked statistical significance.

Interestingly, the methylation pattern in DMR2 discriminated $T_{\text {mem }}$ from $T_{N}$, but was not correlated to $\alpha_{4} \beta_{7}$ expression (Figure 6e and $\mathbf{f}$ ). This suggests that epigenetic opening of this putative regulatory region might already occur with acquisition 
a

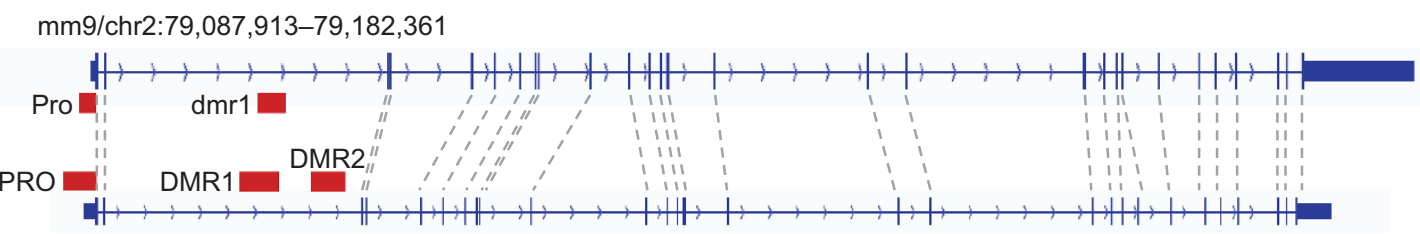

hg19/chr2:182,318,079-182,406,461

b
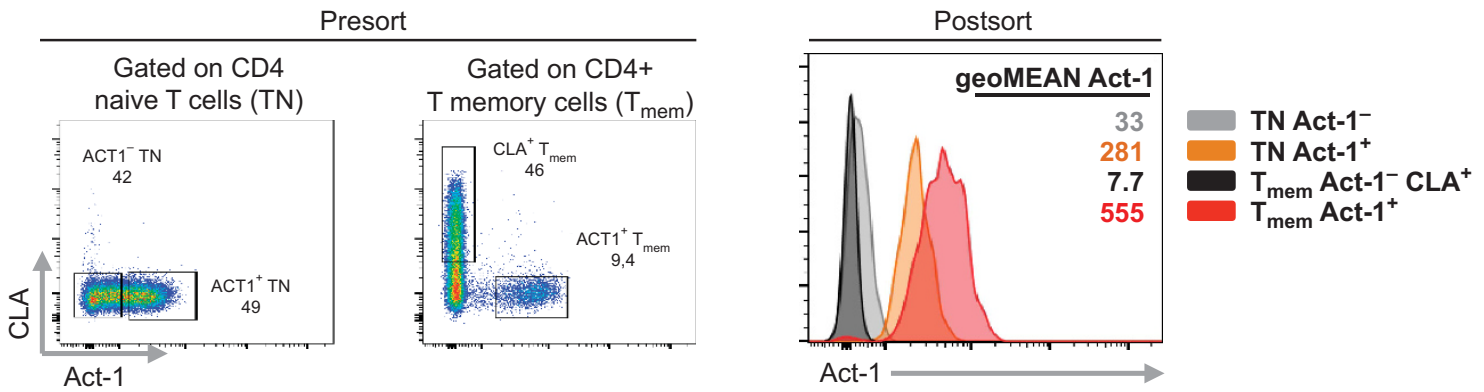

C

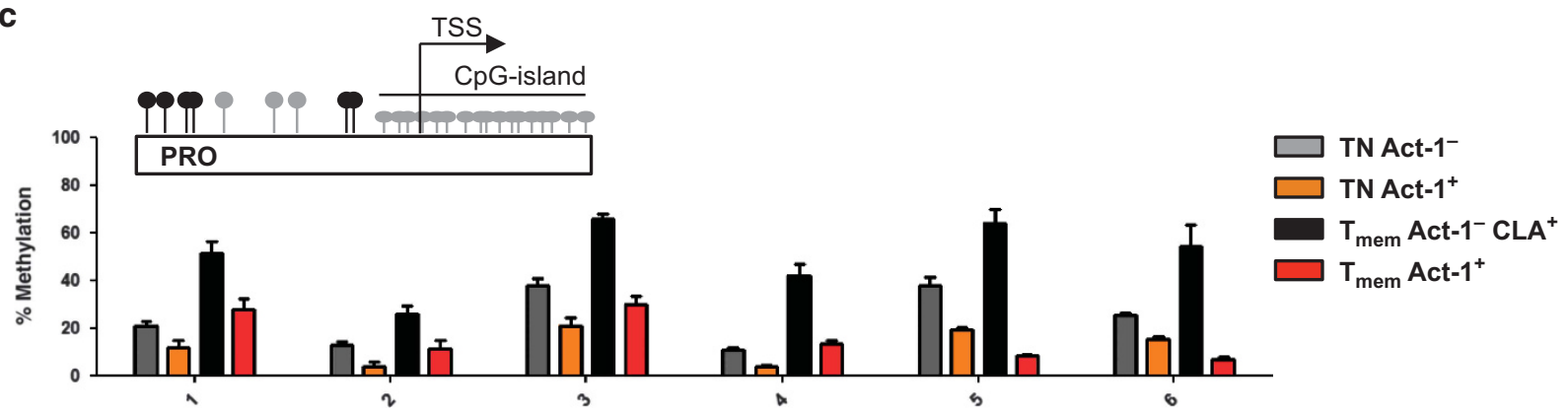

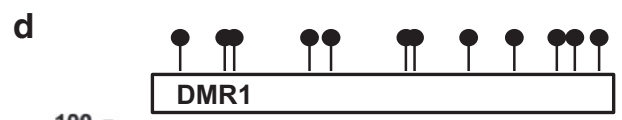

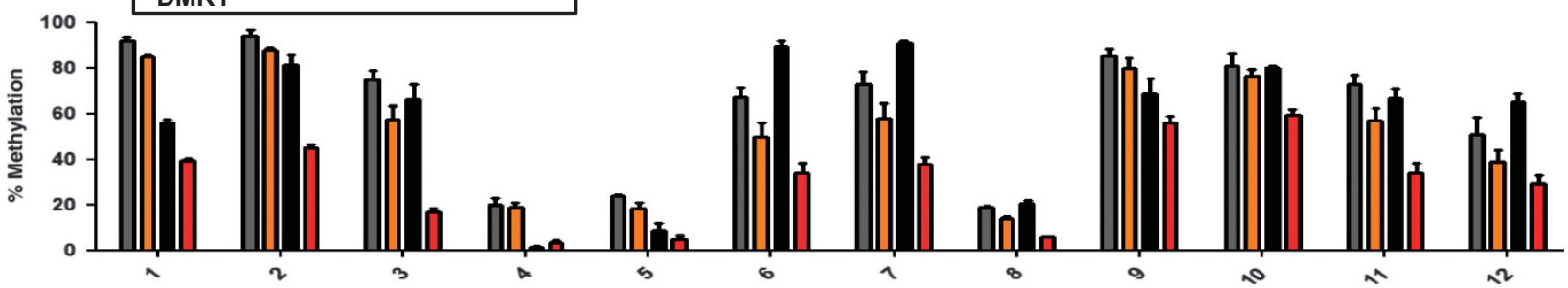

e
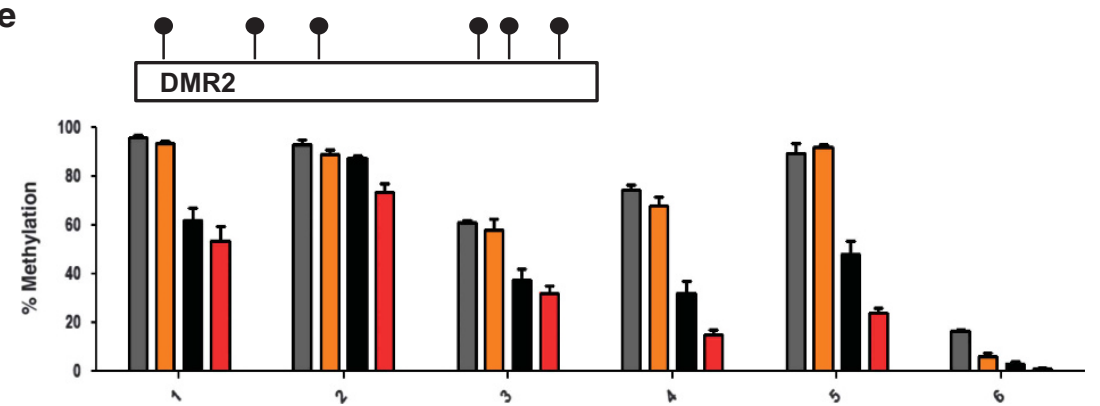

f PRO DMR1

DMR2

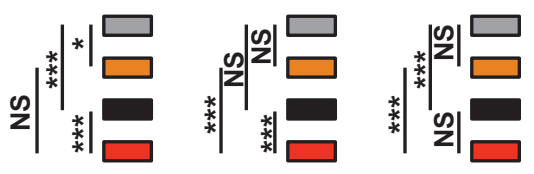

Figure 6 Differential DNA methylation in regulatory regions of the ITGA4 locus in ex vivo human T-cell subsets. (a) Structural similarities of the murine Itga4 (above) and the human ITGA4 (below) locus are shown as well as the positions of the promoters (pro/PRO) and the analyzed differentially methylated regions (differentially methylated region 1 (dmr1)/DMR1/DMR2). (b) Human CD4 ${ }^{+} \mathrm{T}$-cell subsets were sorted according to the gating shown (left). $T_{N}$ and $T_{\text {mem }}$ differ in the level of $\alpha_{4} \beta_{7}$ expressed using the Act- 1 antibody. (c-f) The degree of DNA methylation (mean $\pm \mathrm{s}$.d., $n=3$ ) of selected CpG motifs (shown as black needle heads) in the (c) ITGA4 promoter, (d) DMR1 and (e) DMR2 were analyzed by bisulfite sequencing in the sorted CD4 ${ }^{+}$ T cell subsets shown in (b). (f) Statistical analyses of the DNA methylation differences over all CpGs analyzed in the indicated region. Significant differences are indicated: ${ }^{\star} P \leq 0.05,{ }^{\star \star} P<0.01$, and ${ }^{\star \star \star} P<0.001$; NS, not significant. TSS, transcription start site. 
of a memory state and might allow for expression of ITGA4 also under conditions, where the $\alpha_{4}$-chain, but not the mucosaspecific $\alpha_{4} \beta_{7}$-integrin is expressed. This would contrast to the role of dmr1/DMR1, which seems to regulate the $\alpha_{4}$-chain only in the mucosa-seeking subset of $\mathrm{T}_{\text {mem }}$. In addition, decreased methylation in three regions correlating with upregulated expression in $\mathrm{T}_{\text {mem }}$ cells was also found for ITGB1, coding for the $\beta 1$-integrin chain (Supplementary Figure 6).

\section{DISCUSSION}

The differentiation of T-lymphocytes into memory cells is accompanied by functional specialization, including the acquisition of organ-specific homing capabilities. The present study was designed to answer the question whether, and if so which, cell-intrinsic mechanisms allow T cells primed under appropriate conditions to develop a stable topographical memory for the gut, independent of environmental signals. Our present data demonstrate that indeed an "imprinting for gut homing" is observed for the $\alpha_{4} \beta_{7}$-integrin, which requires repetitive instruction by RA signals. In contrast, stable expression is not inducible for CCR9, at least under the conditions tested here. At the molecular level, this imprinting is based on epigenetic mechanisms, notably regulation of DNA $(\mathrm{CpG}-$ ) methylation at specific regulatory regions of the Itga4 locus.

The mucosal homing receptor $\alpha_{4} \beta_{7}$ integrin is expressed at a low, but functional, level on murine naive lymphocytes and enables their recirculation through gut-associated lymphoid tissues. $^{34}$ Upon activation and differentiation into effector/ memory cells, the population splits up into $T_{\text {mem }}$ that are either completely negative or highly positive for $\alpha_{4} \beta_{7}$, the latter being considered as a stable mucosa-specific memory population. ${ }^{10,35}$ In contrast, Mora et al. ${ }^{16}$ studied the expression of $\alpha_{4} \beta_{7}$ in $\mathrm{CD}^{+} \mathrm{T}$ cells and reported a high degree of plasticity, as freshly generated $\alpha_{4} \beta_{7}^{+}$CD8 ${ }^{+}$T cells could be converted into $\alpha_{4} \beta_{7}^{-}$ cells by restimulation in the presence of subcutanous instead of mucosal DCs, in line with other reports ${ }^{18}$. Moreover, these authors noted that ex vivo-isolated $\mathrm{CD}^{+} \mathrm{T}_{\text {mem }}$ $\left(\mathrm{CCR}^{+} \alpha_{4} \beta_{7}^{+/-} \mathrm{CD} 44^{+}\right.$) were also found to change their $\alpha_{4} \beta_{7}$ expression pattern upon restimulation with the opposite type of DC, suggesting a lack of $\alpha_{4} \beta_{7}$ stability in CD8 ${ }^{+} \mathrm{T}_{\text {mem }}$. More recently, Masopust et al. ${ }^{17}$ observed in a comprehensive study a similar instability of $\alpha_{4} \beta_{7}$ expression on CD8 ${ }^{+}$T cells in vivo. In addition, they found that $\alpha_{4} \beta_{7}$ was efficiently but only transiently upregulated upon in vivo activation, regardless of the site of antigen contact.

With these data, the original paradigm of organ-specific homing ${ }^{1,36}$ was questioned. We now demonstrate that CD4 ${ }^{+} \mathrm{T}$ cells, in contrast, can acquire long-term stability of $\alpha_{4} \beta_{7}$ expression and hence mucosa-specific homing, restoring the validity of the homing concept for this subset. In fact, differences in the migratory program of $\mathrm{CD} 4^{+}$and $\mathrm{CD} 8^{+}$ $\mathrm{T}_{\text {mem }}$ including higher stability of selectin ligands on $\mathrm{CD} 4^{+}$ $\mathrm{T}_{\text {mem }}$ have already been reported ${ }^{15}$ and are now further corroborated by our present data.

RA, produced from the precursor vitamin A by stromal cells, ${ }^{11,37} \mathrm{CD} 103^{+} \mathrm{DCs}^{13,38}$ in gut-associated lymphoid tissues, or by liver sinusoidal cells, ${ }^{39}$ is the key inducer of $\alpha_{4} \beta_{7}$ by regulating the $\alpha_{4}$-chain. ${ }^{30}$ In contrast, basic levels of the $\beta_{7}$-chain are constitutively transcribed in $\mathrm{CD}^{+} \mathrm{T}$ cells, outcompeted by high levels of the $\beta_{1}$-chain and regulated by tumor growth factor- $\beta .^{30,40}$ We have shown here that RA signals are sufficient to induce $\alpha_{4} \beta_{7}$ expression, but the stability of expression (in the absence of RA) is not immediately achieved. Two rounds of in vitro activation in the presence of RA induced a certain degree of stability, yet complete stability with sustained high expression of $\alpha_{4} \beta_{7}$ was found only in ex vivo-isolated $\mathrm{T}_{\mathrm{mem}}$.

Stability in vivo may rely on cell-intrinsic mechanisms, but, alternatively, may be caused by continuous exposure to RA according to three different scenarios: (i) exposure to low levels of RA within the circulation; ${ }^{41}$ (ii) contact with RA-generating antigen-presenting cells during passage through the liver; ${ }^{39}$ (iii) by recirculation through mucosal tissues harboring dendritic cells and/or stromal cells providing RA and/or other unknown instructive signals. However, $\alpha_{4} \beta_{7}$ expression was neither lost upon transfer into RA-depleted animals nor reduced when recirculation of transferred cells through mucosal tissues was blocked. Thus, the findings of this study strongly argue for cell-intrinsic mechanisms being responsible for the imprinting of the mucosal homing phenotype.

How could stability be achieved at a molecular level? A growing body of evidence assigns a key role to the epigenetic machinery in the fixation of phenotypic profiles, as shown for various processes of cell differentiation and lineage commitment. ${ }^{20,33,42}$ In T cells, effector cytokines, master transcription factors and other genes are subject to epigenetic fixation ${ }^{21,22}$ and some indirect hints from our previous work also pointed towards a role in the regulation of homing. ${ }^{14,43}$ In particular, DNA methylation at promoters or enhancers appears to be an attractive mechanism for the regulation of cellular memory by control of chromatin accessibility and transcription factor binding, particularly with respect to the heritability of DNA methylation patterns during mitosis. ${ }^{44}$

The results reported here provide first evidence that stable expression of $\alpha_{4} \beta_{7}$ in the absence of the initial inducer is indeed due to epigenetic regulation at the level of DNA methylation. In both murine and human CD ${ }^{+}$T cells, the Itga4/ITGA4 locus was found to display distinct differentially methylated regions (dmr/DMR) whose degree of methylation correlated with $\alpha_{4} \beta_{7}$ expression, commitment, and/or memory differentiation.

First, several CpGs upstream of the promoter-associated demethylated CpG-I showed distinct differences in methylation. In murine $\mathrm{T}_{\mathrm{N}}$, which express a low but detectable level of $\alpha_{4} \beta_{7},{ }^{35}$ the two CpG upstream of the CpG-I were completely demethylated similar to the $\alpha_{4} \beta_{7}^{+}$fraction of $\mathrm{T}_{\text {mem }}$. Although cells repeatedly stimulated in the presence of RA kept this status, stimulation in the absence of RA as well as in vivo differentiation into $\alpha_{4} \beta_{7}^{-} \mathrm{T}_{\text {mem }}$ resulted in a pronounced methylation. Thus, we conclude that the open conformation of this region enables transcription in both $\mathrm{T}_{\mathrm{N}}$ and $\mathrm{T}_{\text {mem }}$, which, however, seems to be modulated by further regulatory regions, and can be silencend upon differentiation into non-mucosal 
subsets of $\mathrm{T}_{\mathrm{mem}}$. It has to be mentioned that the degree of methylation was not uniform among the CpGs analyzed. Whether this relates to specific functions of single CpGs, e.g., by being part of a distinct transcription factor-binding motif, remains to be investigated. In human cells, for which an $\alpha_{4} \beta_{7}^{+}$ as well as an $\alpha_{4} \beta_{7}^{-}$population can be discriminated among $\mathrm{T}_{\mathrm{N}}$, the latter show moderate methylation, whereas the positive fraction is significantly less methylated. Methylation levels in $\alpha_{4} \beta_{7}^{-} \mathrm{T}_{\text {mem }}$ are much higher than in the $\alpha_{4} \beta_{7}^{+} \mathrm{T}_{\text {mem }}$ fraction. Thus, the suggested regulatory role of $\mathrm{CpG}$ methylation in the promotor-associated region seems to be conserved between mouse and man and to extend to subfractions of naive cells.

Second, differential methylation helped us to identify a novel regulatory region $(\mathrm{dmrl})$ in the murine Itga4 locus that acts as an enhancer. In contrast to the promotor-associated region, the CpG motifs within dmr1 are almost completely methylated in $\mathrm{T}_{\mathrm{N}}$, and there is only a minor, nonsignificant decrease of methylation upon repeated stimulation in the presence of RA, or in $\alpha_{4} \beta_{7}^{+}$vs. $\alpha_{4} \beta_{7}^{-} \mathrm{T}_{\mathrm{N}}$. However, the methylation level was strongly reduced in $\alpha_{4} \beta_{7}^{+} \mathrm{T}_{\text {mem }}$ as compared with $\alpha_{4} \beta_{7}^{-} \mathrm{T}_{\text {mem }}$ or $\mathrm{T}_{\mathrm{N}}$. The enhancer activity of dmr1 was completely abolished by artificial methylation, supporting the functional relevance of DNA methylation in controlling this region. A further hint at the functional role of DNA methylation on regulation of $\alpha_{4} \beta_{7}^{+}$ expression is the stabilizing effect of 5-azacytidine, which blocks DNA methylation; however, indirect effects of this genome-wide-acting inhibitor cannot be excluded.

A related site designated as DMR1 was identified in human $\mathrm{CD}^{+}{ }^{+} \mathrm{T}$ cells, which showed a corresponding demethylation signature correlating to $\alpha_{4} \beta_{7}^{+}$expression. As an additional indication for a conserved mechanism of regulation via dmr1/DMR1, we found the activating histone modification mark H3K4me1 at the human DMR1, indicating that indeed it may serve as an enhancer element (Supplementary Figure 5).

Recently, the transcription factor BATF has been reported to regulate the expression of the $\alpha_{4}$-chain in $\mathrm{CD}^{+}{ }^{+}$cells. ${ }^{45}$ According to the ENCODE data, ${ }^{46}$ BATF binds in a lymphoid cell line at the promoter region; further binding sites for BATF are predicted at the ITGA4 locus including at the DMR1 (using tRap and the jaspar database; data not shown), suggesting BATF as one possible transcription factor involved in $\alpha_{4} \beta_{7}$ stability.

Whole-genome bisulfite sequencing data of the human ITGA4 locus uncovered an additional DMR (DMR2). Similar to dmr1/DMR1, CpGs 1-5 were almost completely methylated in both $\alpha_{4} \beta_{7}^{+}$- and $\alpha_{4} \beta_{7}^{-}$-naive cell subsets, but a highly significant drop in methylation was observed in both memory subsets. Here the differences between $\alpha_{4} \beta_{7}^{+}$and $\alpha_{4} \beta_{7}^{-}$were less prominent and did not reach statistical significance. Hence, this region might be required for expression of the $\alpha_{4}$-chain in $T_{\text {mem }}$ in general (e.g. in $\alpha_{4} \beta_{1}^{+}$, but $\alpha_{4} \beta_{7}^{-}$cells), but additional signals (e.g., from the dmr1/DMR1 enhancer) might regulate it in the mucosa-specific subset.

A subset of effector/memory $\mathrm{T}$ cells expresses the related integrin dimer $\alpha_{4} \beta_{1}$ ("VLA-4"). $\alpha_{4} \beta_{1}$ but not $\alpha_{4} \beta_{7}$ has a key role in multiple sclerosis as this integrin is essential for pathogenic T cells to cross the blood-brain barrier ${ }^{47,48}$ and can be expressed on effector $\mathrm{T}$ cells migrating to further tissues such as the skin and the respiratory track as well. Importantly, expression of $\alpha_{4} \beta_{1}$ and $\alpha_{4} \beta_{7}$ on memory cells is largely mutually exclusive (data not shown). Our findings on the imprinting of the gut-homing phenotype via epigenetic regulation at DMR1 of the ITGA4 gene apply to the $\alpha_{4} \beta_{7}^{+}$subset; $\alpha_{4} \beta_{7}^{-}$P-lig ${ }^{+}$cells, which partially express $\alpha_{4} \beta_{1}$, do not show a demethylated DMR1. However, DMR2, which is demethylated in all memory cells could be a candidate for an epigenetically controlled region regulating $\alpha_{4} \beta_{1}$ in $\alpha_{4} \beta_{7}^{-} \mathrm{T}_{\mathrm{mem}}$ cells. Moreover, first evidence that the ITGB1 locus for his part is also regulated by epigenetic mechanisms can be deduced from the differential methylation in several regions of the human ITGB1 gene correlating with differential expression in $\mathrm{T}_{\mathrm{N}}$ vs. $\mathrm{T}_{\text {mem }}$ (Supplementary Figure 6).

In conclusion, the data of this study confirm the validity of the concept of a topographical memory in $\mathrm{CD} 4^{+} \mathrm{T}_{\mathrm{mem}}$ and provide first evidence that the imprinting of a mucosa-specific homing phenotype involves epigenetic regulation of expression of the $\alpha_{4}$-integrin chain.

\section{METHODS}

Mice. C57Bl/6 and congenic Thy1.1 C57Bl/6 mice were bred at the Bundesinstitut fuer Risikobewertung (Berlin, Germany) and were used at 8-12 weeks of age. BALB/c mice and 7-9-month-old exbreeders were from Charles River WIGA GmbH (Sulzfeld, Germany). All animal experiments were performed under specific pathogen-free conditions and in accordance with institutional, state, and federal guidelines as approved by Landesamt für Gesundheit und Soziales (LaGeSo) Berlin.

Human blood samples. Buffy coats were from DRK-Blutspendedienst Nord-Ost and were used for isolation of human T-cell populations as approved by the local ethics committee (Ethikkommission, Ethikausschuss 1, CCM; application no. EA1/095/13).

Antibodies and cell culture reagents. Antibodies and fusion proteins used were as follows: anti-mCD4 (RM4-5), anti-mCD25 (PC6.1), antimCD45RB (16A), anti-mThy1.1 (OX-7), anti-m $\alpha_{4} \beta_{7}$ (DATK32) and streptavidin PE-Cy7 (all BD Pharmingen, Franklin Lakes, NJ), antihuman IgG (Jackson Immuno Research, West Grove, PA), antimCCR9 (242503; R\&D Systems, Minneapolis, MN), biotinylated anti$\mathrm{m} \alpha_{4} \beta_{7}$ (DATK32, anti-mFc $\gamma$ R II/III (2.4G2), anti-mB220 (RA3.6B2), anti-mMac-1 (M1/70.15.11), anti-mCD8 (53-6.7), anti-mCD3 (145.2C11), anti-mCD28 (37.51), anti-OVA-specific mTCR (KJ1.26), anti-mMAdCAM-1 (Meca367), anti-mVCAM-1 (6C7.1), and antimIL4 (all produced in house), anti-hCD3 (UCHT1), anti-hCD4 (OKT4), anti-hCD45RO (UCHL1), anti-hCLA (HECA-452) (from Biolegend, San Diego, CA), and anti-hCD45RA (2H4LDH11LDB9; Beckman-Coulter, Brea, CA). Recombinant murine P-selectin-huIgG fusion protein used for labeling $\mathrm{P}$-selectin ligand (P-lig) was kindly provided by D Vestweber (Münster, Germany). The anti-human $\alpha_{4} \beta_{7}$ antibody Act-1 was provided by Millenium at Takeda Pharmaceutical Company (Cambridge, MA) and PE-conjugated in-house. Microbeads were from Miltenyi Biotec (Bergisch Gladbach, Germany). Mouse recombinant IL-2 (rmIL-2), rmIL-12, and rmIFN $\gamma$ (interferon- $\gamma$ ) were from R\&D Systems, all-trans RA and ovalbumin and cholera toxin were from Sigma-Aldrich, St. Louis, MO, pan-RA receptor antagonist LE540 was from Wako Chemicals (Neuss, Germany). Cell culture was performed in RPMI-1640 (Gibco, Carlsbad, CA and PAA (Cölbe, Germany)) supplemented with $10 \%$ fetal calf serum (Sigma).

Flow cytometry. For flow cytometry an LSRII (BD Biosciences, Franklin Lakes, NJ) and FlowJo software were used. Gates were set according to FMO (fluorescence minus one) stainings with or without 
isotype controls. Cell sorting was performed on FACSAria I or II Cell Sorter BD, Franklin Lakes, NJ.

Isolation of ex vivo murine and human T cells. For in vitro culture of murine $\mathrm{CD}^{+}{ }^{+} \mathrm{T}_{\mathrm{N}}$, pooled erythrocyte-depleted spleen and lymph node cells from $\mathrm{BALB} / \mathrm{c}, \mathrm{C} 57 \mathrm{Bl} / 6$, or Thy1.1 congenic $\mathrm{C} 57 \mathrm{Bl} / 6$ mice were stained with anti-mCD4-FITC and anti-mCD25-APC antibodies and depleted of $\mathrm{CD} 25^{+}$cells using anti-APC microbeads and the AutoMACS magnetic separation system (Miltenyi Biotec). Subsequently, CD $25^{-}$cells were positively enriched for $\mathrm{CD} 4^{+} \mathrm{T}$ cells using anti-FITC multisort beads. Release reagent and anti-CD62L microbeads were used to obtain $\mathrm{CD} 25^{-} \mathrm{CD} 4^{+} \mathrm{CD} 62 \mathrm{~L}^{\text {high }} \mathrm{T}$ cells.

For the isolation of murine $\mathrm{CD} 4{ }^{+} \mathrm{T}_{\text {mem }}$, pooled spleen, peripheral, and mesenteric lymph node cells from 20 to $40 \mathrm{BALB} / \mathrm{c}$ exbreeder mice were negatively selected with anti-mCD8, anti-mMac-1, and anti-mB220 antibodies and anti-rat-IgG microbeads. Enriched CD4 ${ }^{+} \mathrm{T}$ cells were labeled with anti-CD45RB FITC and depleted of CD45RB ${ }^{\text {hi }}$ cells using anti-FITC microbeads. Subsequently, $\alpha_{4} \beta_{7}^{+} \mathrm{P}-\mathrm{lig}{ }^{-} \mathrm{CD} 45 \mathrm{RB}{ }^{\text {low }} \mathrm{CD} 4{ }^{+}$ and $\alpha_{4} \beta_{7}^{-} \mathrm{P}$-lig ${ }^{-} \mathrm{CD} 45 \mathrm{RB}^{\text {low }} \mathrm{CD}^{+}{ }^{+} \mathrm{T}$ cells were sorted by flow cytometry. For methylation analyses, the $\alpha_{4} \beta_{7}^{-} \mathrm{P}$-lig ${ }^{+}$subset ("inflammation/skin-specific subset") was sorted as the $\alpha_{4} \beta_{7}^{-}$subset.

For isolation of human $\mathrm{T}$ cells, peripheral blood mononuclear cells were isolated by density gradient centrifugation using Lymphocyte Separation Medium LSM 1077 (PAA, Cölbe, Germany) from buffy coats. Erythrocytes were lysed in erythrocyte lysis buffer (Buffer EL; Qiagen, Venlo, Niederlande). CD4 ${ }^{+}$T-lymphocytes were enriched using CD4 MicroBeads (Miltenyi Biotec). The enriched population was stained and sorted by flow cytometry into four populations:

$\mathrm{T}_{\mathrm{N}}$ Act- $1^{-}=\mathrm{CD}^{+}{ }^{+} \mathrm{CD} 4{ }^{+} \mathrm{CD}^{-} 5 \mathrm{RA}^{+}{ }^{+} \mathrm{CD} 45 \mathrm{RO}^{-}{ }^{-}$Act- $1^{-} \mathrm{CLA}^{-}$; $\mathrm{T}_{\mathrm{N}} \mathrm{Act}^{+}{ }^{+}=\mathrm{CD}^{+}{ }^{+} \mathrm{CD} 4{ }^{+} \mathrm{CD}_{45 \mathrm{RA}}{ }^{+} \mathrm{CD} 45 \mathrm{RO}^{-}$Act $-1^{+} \mathrm{CLA}^{-}$; $\mathrm{T}_{\text {mem }}$ Act- ${ }^{-} \quad \mathrm{CLA}^{+}=\mathrm{CD}^{+} \mathrm{CD}^{+}{ }^{+} \mathrm{CD}_{4} 5 \mathrm{RA}^{-} \mathrm{CD}^{-} 5 \mathrm{RO}^{+} \mathrm{Act}^{-} 1^{-}$ $\mathrm{CLA}^{+}$;

$\mathrm{T}_{\text {mem }}$ Act- $1^{+}=\mathrm{CD}^{+}{ }^{+} \mathrm{CD} 4{ }^{+} \mathrm{CD}_{45 \mathrm{RA}}{ }^{-} \mathrm{CD} 45 \mathrm{RO}^{+} \mathrm{Act}^{+}{ }^{+} \mathrm{CLA}^{-}$.

Purity of the sorted populations was confirmed by flow cytometry and $>95 \%$.

In vitro cell cultures. Murine naive $\mathrm{CD} 25^{-} \mathrm{CD} 4{ }^{+} \mathrm{CD} 62 \mathrm{~L}^{\text {high }} \mathrm{T}$ cells were stimulated on plate-bound anti-mCD3 $\left(1-4 \mu \mathrm{g} \mathrm{ml}^{-1}\right)$ and antimCD28 $\left(4-8 \mu \mathrm{g} \mathrm{ml}^{-1}\right)$ antibodies or via irradiated APCs with soluble anti-mCD3 and anti-mCD28 in the presence of rmIL-2 $\left(10 \mathrm{ng} \mathrm{ml}^{-1}\right)$ either under neutral (no further supplements) or under Th1 polarizing conditions (rmIL-12 (5 ng ml $\left.{ }^{-1}\right), \operatorname{rmIFN} \gamma\left(20 \mathrm{ng} \mathrm{ml}^{-1}\right)$, anti-mIL-4 $\left(5 \mu \mathrm{g} \mathrm{ml}^{-1}\right)$ ), with or without the addition of RA (1 nM) or LE540 $(0.25 \mu \mathrm{M}$, to block medium-derived RA). On day 3 of culture, T cells were removed from the stimulus and rested for another 1-3 days. Cells were analyzed for $\alpha_{4} \beta_{7}$ expression on the indicated days and restimulated for prolonged culture periods on days 5 and 11 . In contrast to $\mathrm{T}_{\mathrm{N}}$, ex vivo isolated $\mathrm{T}_{\text {mem }}$ were stimulated with reduced levels of plate-bound anti-mCD3 $\left(1 \mu \mathrm{g} \mathrm{ml}^{-1}\right)$ and anti-mCD28 $\left(2 \mu \mathrm{g} \mathrm{ml}^{-1}\right)$ for $12-16 \mathrm{~h}$ and subsequently rested until restimulation.

Analysis of homing receptor expression on adoptively transferred T cells. A total of $1.5-3 \times 10^{6}$ cultured $\mathrm{CD} 4{ }^{+} \mathrm{T}$ cells (day 11 of culture) or ex vivo isolated, CFSE-labeled or Thy1.1/2 congenic $\mathrm{T}_{\text {mem }}$ were injected into the tail vein of recipients. On day 15 or 6 weeks after T-cell transfer, recipient mice were killed and cells from spleen, $\mathrm{pLN}$, and mLNs were stained for CD4, Thy1.1, and $\alpha_{4} \beta_{7}$. At these time points, between 0.12 and $0.05 \%$ of the $\mathrm{CD} 4{ }^{+} \mathrm{T}$ cells in lymphoid organs were donor-derived.

Generation of vitamin A-deficient mice. Female mice received a vitamin A-deficient (ssniff Spezialdiäten $\mathrm{GmbH}$, Soest, Germany) or control diet 10 days after initial mating (embryonic days 7-10). Offspring was weaned at 3 weeks of age and on diet until 19 weeks of age before transfer of $\mathrm{T}_{\text {mem }}$. To verify depletion of vitamin A, CFSElabeled OVA-specific CD4 ${ }^{+} \mathrm{CD}_{2} \mathrm{~L}^{\text {high }} \mathrm{T}$ cells from DO11.10 mice were transferred to mice fed vitamin A-reduced or control diet. On day 1 after transfer, mice were immunized with $100 \mathrm{mg}$ OVA protein and
$10 \mu \mathrm{g}$ cholera toxin (both Sigma-Aldrich) by oral gavage. Four days after immunization, $\alpha_{4} \beta_{7}$ and CCR9 expression were analyzed on OVA-specific $\left(\mathrm{KJ}^{+}\right)$mLN cells.

Exclusion of $\alpha_{4} \beta_{7}^{+} \mathbf{T}_{\text {mem }}$ from GALT. To exclude $\alpha_{4} \beta_{7}^{+} \mathrm{T}_{\text {mem }}$ from GALT, recipient mice received either rat IgG or anti-MAdCAM-1 (Meca367; $500 \mu \mathrm{g}$ per mouse) plus anti-VCAM-1 (6C7.1; $200 \mu \mathrm{g}$ per mouse) antibodies intravenously every 3 days. This treatment started on the day of transfer and was maintained until the analysis of $\alpha_{4} \beta_{7}$ expression on day 15.

Generation of luciferase reporter vectors. The Itg $\alpha 4$ inserts were amplified by PCR using mouse genomic DNA and the following primers (Eurofins, Hamburg, Germany): Itga4 promoter_fwd: $5^{\prime}$-CTG GTGGTAGGTATGTCCTGGGGT-3' and Itga4 promoter_rev: $5^{\prime}$-CG CTCTTGGTGGAGAACATT- $3^{\prime}$; dmr1_fwd: $5^{\prime}$-TCAGATTTTGCTA GCCATCCT- $3^{\prime}$ and dmr1_rev: $5^{\prime}$-TGCTTCCCACAATTCTAAAA CA- $3^{\prime}$. PCR fragments for the Itga 4 promoter and dmr 1 were cloned into the pGL3-basic luciferase reporter vector (Promega, Madison, WI, USA). For the generation of a reporter vector for $\mathrm{dmr} 1$ in a CpG-free background, ${ }^{32}$ the dmr1 region was inserted into the pCpGL-EF1 vector. ${ }^{49}$ Endotoxin-free plasmid DNA for transfection was purified using NucleoBond Xtra Maxi EF (Macherey-Nagel, Düren, Germany).

Luciferase reporter assay. Murine-naive CD $25^{-} \mathrm{CD} 4{ }^{+} \mathrm{CD} 62 \mathrm{~L}^{\text {high }} \mathrm{T}$ cells were stimulated for two days using plate-bound antibodies and polarized towards Th1 as described above. A total of $1 \times 10^{6}$ in vitroinduced C57Bl/6 Th1 cells were transfected with equimolar amounts $(3.12 \mathrm{pmol})$ of the reporter plasmids using the Neon transfection device (Life Technologies, Carlsbad, CA) applying two pulses (voltage: $1,350 \mathrm{~V}$; width: $20 \mathrm{~ms}$ ). Fifty nanograms of the pRL-CMV vector (Promega) containing the Renilla luciferase cDNA were co-transfected and used as an internal control for transfection efficiency. Cells were cultured for another $24 \mathrm{~h}$ with and another $24 \mathrm{~h}$ without plate-bound stimulation antibodies. Cells were harvested and luciferase activity was measured using the Dual-Luciferase Reporter Assay System (Promega). After normalization of firefly activity to Renilla activity, relative firefly activity was normalized to activity of the empty vector.

In vitro methylation of luciferase reporter plasmids. Thirty micrograms of plasmid DNA were incubated with M.Sss I $\left(2.5 \mathrm{U} \mathrm{\mu g}^{-1}\right.$ DNA) in the presence of $160 \mu \mathrm{M} S$-adenosylmethionine for $4 \mathrm{~h}$ at $37^{\circ} \mathrm{C}$, with another $160 \mu \mathrm{M} S$-adenosylmethionine added after the first $2 \mathrm{~h}$ of incubation. Mock-methylated plasmids were treated identically but without the enzyme and $S$-adenosylmethionine. Plasmid DNA was purified using the NucleoSpinExtract II Kit (Macherey-Nagel). Successful methylation was verified with the methylation-sensitive restriction enzyme HpaII.

DNA methylation analysis by bisulfite sequencing. Bisulfite sequencing for murine and human samples was performed according to Gries et al. ${ }^{50}$ (primers in Supplementary Table 1). Briefly, $300 \mathrm{ng}$ genomic DNA was bisulfite treated using the EZ DNA Methylation Kit (Zymo Research, Irvine, CA, USA). PCRs were performed using primers with a specific $3^{\prime}$-portion and a universal $5^{\prime}$-portion according to Illumina's specifications (specific portion of primer sequences are listed in Supplementary Table 1). Amplicons were purified using AGENCOURT Ampurebeads (Beckman/Coulter), diluted, and pooled. Deep sequencing was performed on the Illumina (San Diego, CA) MiSeq according to the manufacturer's protocols aiming at 10,000 reads per amplicon. Reads were processed and aligned using the BiQ Analyzer HT software (http://www.mpi-inf.mpg.de) ${ }^{51}$ setting the maximal fraction of unrecognized sites' filter at 0.1 .

Statistics. If not indicated otherwise, data are presented as mean \pm s.d. or mean \pm s.e.m.). Significance was determined with Student's $t$-test, after testing of normal distribution by the Kolmogorov-Smirnov test. Differences were considered statistically significant with ${ }^{\star} P \leq 0.05$, ${ }^{* *} P<0.01$, and ${ }^{* *} P<0.001$ Differences in DNA methylation were 
analyzed by computing differences of permuted methylation levels on each CpG site. Statistical significance was determined by applying onesample, one-tailed Student's $t$-test on the differences in all CpG in the respective region, with the alternative hypothesis of true methylation difference assumed as $>10 \%$ or $<-10 \%$. Significance levels $\left({ }^{\star} P \leq 0.05,{ }^{* *} P<0.01\right.$, and $\left.{ }^{* *} P<0.001\right)$ were in accordance with the nonparametric, one-sample Wilcoxon's signed-rank test with similar settings.

SUPPLEMENTARY MATERIAL is linked to the online version of the paper at http://www.nature.com/mi

\section{ACKNOWLEDGMENTS}

We thank the Flow Cytometry Core Facility at the DRFZ for expert cell sorting, Uta Lauer and René Maier for expert technical assistance, Claudia Berek and Chu Van Trung, DRFZ Berlin, for their help with the generation of vitamin A-deficient mice, Makoto Iwata, Tokushima Bunri University, for fruitful discussions, and Millenium Pharmaceuticals/Takeda Pharmaceutical Company for kindly supplying the anti-human $\alpha_{4} \beta_{7}$ antibody Act-1. This study was supported by grants of the Deutsche Forschungsgemeinschaft, SFB633-B1, SFB650 TP1, and Ha 1505/10-1, and by the German Epigenome Programme (DEEP) of the Federal Ministry of Education and Research (BMBF).

\section{AUTHOR CONTRIBUTIONS}

B.S., J.T., M.M., and A.S. performed functional T-cell analyses; J.T., C.K., M.d.A., M.M., and S.F. were involved in epigenetic analyses; S.T. generated bisulfite-seq data, P.D. performed bioinformatic analyses, A.H. and J.K.P. designed and coordinated the study; B.S., A.H., and J.K.P. wrote the manuscript with contributions from JW, US, and other authors.

\section{DISCLOSURE}

The authors declared no conflict of interest.

c 2017 Society for Mucosal Immunology

\section{REFERENCES}

1. Gowans, J.L. The recirculation of lymphocytes from blood to lymph in the rat. J. Physiol. 146, 54-69 (1959).

2. Rott, L.S., Rose, J.R., Bass, D., Williams, M.B., Greenberg, H.B. \& Butcher, E.C. Expression of mucosal homing receptor $\alpha 4 \beta 7$ by circulating CD4 ${ }^{+}$ cells with memory for intestinal rotavirus. J. Clin. Invest. 100, 1204-1208 (1997).

3. Rose, J.R., Williams, M.B., Rott, L.S., Butcher, E.C. \& Greenberg, H.B. Expression of the mucosal homing receptor $\alpha 4 \beta 7$ correlates with the ability of $\mathrm{CD}^{+}{ }^{+}$memory T cells to clear rotavirus infection. J. Virol. $72,726-730$ (1998).

4. Santamaria Babi, L.F. et al. Circulating allergen-reactive $T$ cells from patients with atopic dermatitis and allergic contact dermatitis express the skin-selective homing receptor, the cutaneous lymphocyte-associated antigen. J. Exp. Med. 181, 1935-1940 (1995).

5. Masopust, D., Vezys, V., Marzo, A.L. \& Lefrancois, L. Preferential localization of effector memory cells in nonlymphoid tissue. Science 291, 2413-2417 (2001).

6. Reinhardt, R.L., Khoruts, A., Merica, R., Zell, T. \& Jenkins, M.K. Visualizing the generation of memory CD4 T cells in the whole body. Nature 410, 101105 (2001).

7. Mora, J.R. \& von Andrian, U.H. T-cell homing specificity and plasticity: new concepts and future challenges. Trends Immunol. 27, 235-243 (2006).

8. Sigmundsdottir, H. \& Butcher, E.C. Environmental cues, dendritic cells and the programming of tissue-selective lymphocyte trafficking. Nat. Immunol. 9, 981-987 (2008).

9. Sheridan, B.S. \& Lefrancois, L. Regional and mucosal memory T cells. Nat/ Immunol. 12, 485-491 (2011).

10. Campbell, D.J. \& Butcher, E.C. Rapid acquisition of tissue-specific homing phenotypes by $\mathrm{CD} 4^{+}$T cells activated in cutaneous or mucosal lymphoid tissues. J. Exp. Med. 195, 135-141 (2002).
11. Molenaar, R. et al. Lymph node stromal cells support dendritic cell-induced gut-homing of T cells. J. Immunol. 183, 6395-6402 (2009).

12. Coombes, J.L., Robinson, N.J., Maloy, K.J., Uhlig, H.H. \& Powrie, F. Regulatory T cells and intestinal homeostasis. Immunol Rev 204, 184-194 (2005)

13. Iwata, M., Hirakiyama, A., Eshima, Y., Kagechika, H., Kato, C. \& Song, S.Y. Retinoic acid imprints gut-homing specificity on Tcells. Immunity 21, $527-$ 538 (2004).

14. Jennrich, S., Ratsch, B.A., Hamann, A. \& Syrbe, U. Long-term commitment to inflammation-seeking homing in $\mathrm{CD}^{+}{ }^{+}$effector cells. J Immunol 178, 8073-8080 (2007).

15. Gebhardt, T. et al. Different patterns of peripheral migration by memory CD4 $\left({ }^{+}\right)$and CD8 $\left.{ }^{+}\right)$T cells. Nature 477, 216-219 (2011).

16. Mora, J.R., Cheng, G., Picarella, D., Briskin, M., Buchanan, N. \& von Andrian, U.H. Reciprocal and dynamic control of CD8 T cell homing by dendritic cells from skin- and gut-associated lymphoid tissues. J. Exp. Med. 201, 303-316 (2005).

17. Masopust, D. et al. Dynamic T cell migration program provides resident memory within intestinal epithelium. J. Exp. Med. 207, 553-564 (2010).

18. Dudda, J.C. et al. Dendritic cells govern induction and reprogramming of polarized tissue-selective homing receptor patterns of T cells: important roles for soluble factors and tissue microenvironments. Eur. J. Immunol. 35 , 1056-1065 (2005).

19. Kanno, Y., Vahedi, G., Hirahara, K., Singleton, K. \& O'Shea, J.J. Transcriptional and epigenetic control of $\mathrm{T}$ helper cell specification: molecular mechanisms underlying commitment and plasticity. Annu. Rev. Immunol. 30, 707-731 (2012).

20. Morikawa, H. \& Sakaguchi, S. Genetic and epigenetic basis of Treg cell development and function: from a FoxP3-centered view to an epigenome-defined view of natural Treg cells. Immunol. Rev. 259, 192-205 (2014).

21. Huehn, J., Polansky, J.K. \& Hamann, A. Epigenetic control of FOXP3 expression: the key to a stable regulatory T-cell lineage?. Nat. Rev. Immunol. 9, 83-89 (2009).

22. Wei, G. et al. Global mapping of $\mathrm{H} 3 \mathrm{~K} 4 \mathrm{me} 3$ and $\mathrm{H} 3 \mathrm{~K} 27 \mathrm{me} 3$ reveals specificity and plasticity in lineage fate determination of differentiating CD4 + T cells. Immunity 30, 155-167 (2009).

23. Naito, T. \& Taniuchi, I. Roles of repressive epigenetic machinery in lineage decision of T cells. Immunology 139, 151-157 (2012).

24. Mackay, C.R., Marston, W.L. \& Dudler, L. Naive and memory T cells show distinct pathways of lymphocyte recirculation. J. Exp. Med. 171, 801-817 (1990).

25. Sparshott, S.M. \& Bell, E.B. Lymphocyte trafficking: CD4 T cells with a 'memory' phenotype (CD45RC-) freely cross lymph node high endothelial venules in vivo. Immunology 93, 447-454 (1998).

26. Austrup, F. et al. P-and E-selectin mediate recruitment of T helper 1 but not T helper 2 cells into inflamed tissues. Nature 385, 81-83 (1997).

27. Wagers, A.J., Waters, C.M., Stoolman, L.M. \& Kansas, G.S. Interleukin 12 and interleukin 4 control T cell adhesion to endothelial selectins through opposite effects on alpha1, 3-fucosyltransferase VII gene expression. J. Exp. Med. 188, 2225-2231 (1998).

28. Mora, J.R. \& von Andrian, U.H. Retinoic acid: an educational 'vitamin elixir' for gut-seeking T cells. Immunity 21, 458-460 (2004).

29. Johansson-Lindbom, B. \& Agace, W.W. Generation of gut-homing T cells and their localization to the small intestinal mucosa. Immunol. Rev. 215, 226-242 (2007)

30. Kang, S.G., Park, J., Cho, J.Y., Ulrich, B. \& Kim, C.H. Complementary roles of retinoic acid and TGF- $\beta 1$ in coordinated expression of mucosal integrins by T cells. Mucosal Immunol. 4, 66-82 (2011).

31. Irizarry, R.A. et al. The human colon cancer methylome shows similar hypo- and hypermethylation at conserved tissue-specific $\mathrm{CpG}$ island shores. Nat. Genet. 41, 178-186 (2009).

32. Klug, M. \& Rehli, M. Functional analysis of promoter $\mathrm{CpG}$ methylation using a CpG-free luciferase reporter vector. Epigenetics 1, 127-130 (2006).

33. Durek, P. et al. Epigenomic profiling of human $\mathrm{CD} 4^{+} \mathrm{T}$ cells supports a linear differentiation model and highlights molecular regulators of memory development. Immunity 45, 1148-1161 (2016).

34. Hamann, A., Andrew, D.P., Jablonski-Westrich, D., Holzmann, B. \& Butcher, E.C. Role of a4-Integrins in lymphocyte homing to mucosal tissues in vivo. J. Immunol. 152, 3282-3293 (1994). 
35. Williams, M.B. \& Butcher, E.C. Homing of naive and memory T lymphocyte subsets to Peyer's patches, lymph nodes, and spleen. J. Immunol. 159, 1746-1752 (1997).

36. Butcher, E.C. \& Picker, L.J. Lymphocyte homing and homeostasis. Science 272, 60-66 (1996).

37. Hammerschmidt, S.l. et al. Stromal mesenteric lymph node cells are essential for the generation of gut-homing T cells in vivo. J. Exp. Med. 205, 2483-2490 (2008).

38. Coombes, J.L. et al. A functionally specialized population of mucosal CD103 + DCs induces Foxp3 + regulatory T cells via a TGF- $\beta$ and retinoic acid-dependent mechanism. J. Exp. Med. 204, 1757-1764 (2007).

39. Neumann, K. et al. Connecting liver and gut: murine liver sinusoidal endothelium induces gut tropism of $\mathrm{CD}^{+}{ }^{+} \mathrm{T}$ cells via retinoic acid. Hepatology 55, 1976-1984 (2012).

40. DeNucci, C.C., Pagan, A.J., Mitchell, J.S. \& Shimizu, Y. Control of $\alpha 4 \beta 7$ integrin expression and CD4 T cell homing by the beta1 integrin subunit. J. Immunol. 184, 2458-2467 (2010).

41. Eckhoff, C. \& Nau, H. Identification and quantitation of all-trans- and 13-cis-retinoic acid and 13-cis-4-oxoretinoic acid in human plasma. J. Lipid Res. 31, 1445-1454 (1990).

42. Zhu, J. et al. Genome-wide chromatin state transitions associated with developmental and environmental cues. Cell 152, 642-654 (2013).

43. Syrbe, U., Jennrich, S., Schottelius, A., Richter, A., Radbruch, A. \& Hamann, A. Differential regulation of $\mathrm{P}$-selectin ligand expression in naïve versus memory $\mathrm{T}$ cells: evidence for epigenetic regulation of involved glycosyltransferase genes. Blood 104, 3243-3248 (2004).

44. Bird, A. DNA methylation patterns and epigenetic memory. Genes Dev. 16, 6-21 (2002).

45. Wang, C. et al. BATF is required for normal expression of gut-homing receptors by $\mathrm{T}$ helper cells in response to retinoic acid. J. Exp. Med. 210, 475-489 (2013).

46. Gerstein, M.B. et al. Architecture of the human regulatory network derived from ENCODE data. Nature 489, 91-100 (2012).

47. Yednock, T.A., Cannon, C., Fritz, L.C., Sanchez, M.F., Steinman, L. \& Karin, N. Prevention of experimental autoimmune encephalomyelitis by antibodies against alpha 4 beta 1 integrin. Nature 356, 63-66 (1992).

48. Doring, A. et al. TET inducible expression of the $\alpha 4 \beta 7$-integrin ligand MAdCAM-1 on the blood-brain barrier does not influence the immunopathogenesis of experimental autoimmune encephalomyelitis. Eur. J. Immunol. 41, 813-821 (2011).

49. Polansky, J.K. et al. Methylation matters: binding of Ets-1 to the demethylated Foxp3 gene contributes to the stabilization of Foxp3 expression in regulatory T cells. J. Mol. Med. (Berl) 88, 1029-1040 (2010).

50. Gries, J. et al. Bi-PROF: bisulfite profiling of target regions using 454 GS FLX Titanium technology. Epigenetics 8, 765-771 (2013).

51. Lutsik, P., Feuerbach, L., Arand, J., Lengauer, T., Walter, J. \& Bock, C. BiQ Analyzer HT: locus-specific analysis of DNA methylation by highthroughput bisulfite sequencing. Nucleic Acids Res. 39, W551-W556 (2011). 